\title{
El impacto de la imagen física de los artistas escénicos
}

Por Kevin Francisco Cruz Reyes

Alumno de la Licenciatura en Música

Nuestros resultados indican que la mayoría de los artistas escénicos están conscientes que la apariencia sí importa y mucho, pero solo el 42 por ciento está dispuesto a hacer algo para mejorarla.

$K C R$

\section{Introducción}

Este trabajo de investigación presenta el impacto que tiene la imagen física de un artista escénico en la toma de decisiones de los empleadores... Un tema relevante para el ámbito laboral y poco abordado en los currículos educativos profesionales. Esperamos que estos resultados contribuyan en la formación profesional del artista. Para su desarrollo, hemos seguido un método mixto, aplicando encuestas a una población de estudiantes del Departamento de Bellas Artes y entrevistando a personajes claves de la industria cultural y artística de nuestro país. A partir de ello, este artículo presenta los resultados obtenidos, informando acerca de cómo influye la imagen física en su formación y profesión.

\section{El impacto de la imagen del artista escé- nico}

Actualmente, observamos la gran importancia que se le da a la apariencia física del artista escénico, sea en el ámbito comercial o no... Tal observación, nos permite plantearnos la siguiente pregunta: ¿Cuál es el impacto que tiene la imagen de un artista escénico actualmente?

Albert Mehrabian, un estudioso del tema de la imagen, señala que la eficiencia de la comunicación radica más en la "forma" que en el "fondo". Ese autor le atribuye un 93 por ciento a la forma y únicamente un 7 por ciento al fondo. Según Moreno (2015), Mehrabian se refiere a la forma como la manera física en que viaja un mensaje y al fondo como la esencia del mensaje. La forma puede a su vez separarse en apariencia y en la manera en que viajan los mensajes. Así, de ese 93 por ciento, el 55 por ciento es la apariencia y el 38 por ciento la manera en cómo se transmite un mensaje. En el terreno de la imagen física, forma será nuestra apariencia y fondo nuestra esencia personal. Esto nos da una primera visión de lo importante que es la apariencia física y del impacto psicológico que tiene en el receptor.

Daniel Hamermesh, economista de la Universidad de Texas, calcula que "un trabajador guapo ganará a lo largo de su carrera $\$ 3$ millones 300 mil pesos más que otro con las mismas características, pero con un aspecto más insípido". (Como se cita en Gordoa, 2016)

Estos estudios nos llevan a formular varias preguntas: ¿la apariencia física de los artistas escénicos realmente importa? Y si es así, ¿los artistas están conscientes de ello? Para dar una primera respuesta a estas preguntas, en el mes de noviembre de 2015 realicé encuestas a 50 estudiantes de las licenciaturas en artes escénicas y música de

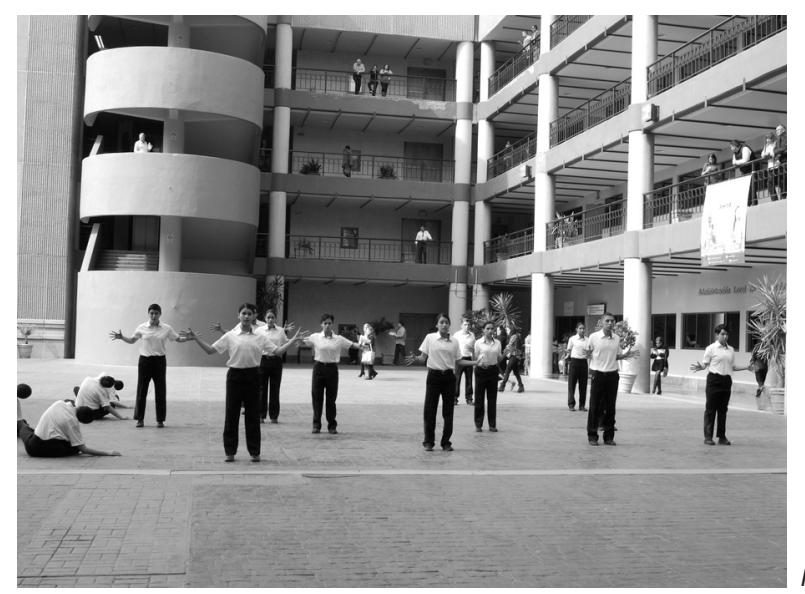

Fotografia: Ana Isabel Campillo 
la Universidad de Sonora, de los cuales el 50 por ciento son mujeres y 50 por ciento hombres. Se trata de una encuesta de 12 preguntas.

Según los resultados obtenidos el 86 por ciento de los encuestados consideran que su imagen física es muy importante en un 76 por ciento. El 68 por ciento considera que a las personas con una buena apariencia física les va mejor. El 60 por ciento de los encuestados dice que su apariencia física ha sido importante para abrir o cerrar puertas en más del 50 por ciento de las ocasiones. Sin embargo, sólo el 42 por ciento de ellos están dispuestos a esforzarse en su maquillaje y vestuario antes de salir a escena. El 37 por ciento de las mujeres no están dispuestas a preocuparse por su apariencia física. Estos resultados indican que la mayoría de los artistas escénicos están conscientes de que la apariencia sí importa y mucho, pero solo el 42 por ciento está dispuesto a hacer algo para mejorarla.

Tal como lo dice el autor Álvaro Gordoa en su libro Imagen Cool (2007): "La imagen tiene el poder de producir efectos en la conducta de las personas, ya que se une a una opinión que va a influir en sus preferencias y decisiones" (p. 33). Por lo tanto, si un artista escénico no se preocupa por lo que su imagen está proyectando en el escenario difícilmente el público lo aprobará o lo contratarán.

¿Cómo podemos definir la imagen? Según el experto Víctor Gordoa, en su obra Imagen Vendedora (2007), "Imagen es la percepción que se convierte en la identidad de lo percibido, y la percepción se convierte en una realidad, las cosas son lo que parecen aunque en realidad no lo sean" (p. 58). Ésta definición muestra lo importante que es cuidar nuestra imagen y da la idea de que si podemos manejarla seremos capaces de cambiar la manera en que somos percibidos.

¿Qué es lo que realmente logra una buena impresión a través de la imagen física? Por supuesto la emisión correcta de los mensajes que queremos transmitir. Debe existir una coherencia entre lo que somos y lo que parecemos, fondo y forma en completa armonía. Si logramos esta coherencia entre el fondo y la forma ganaremos credibilidad. "A través de la percepción otorgamos identidad a las cosas, si lo que percibiste te gusta, entonces lo identi

ficarás para ti, si te desagrada, entonces lo identificarás como malo" (Gordoa, 2007, p. 58).

Para completar la investigación acerca del impacto de la imagen, entrevisté a algunos maestros de artes de la Universidad de Sonora y a personas destacadas en nuestro país que se dedican a crear figuras del escenario, todos ellos concuerdan que es importante que también los artistas en formación se preocupen por su imagen.

María Collura, por ejemplo, es una productora, Coach y Talent Scout del área musical. Ella opina que una buena imagen física correctamente gestionada se convierte en una ventaja competitiva": "Las figuras del escenario no necesariamente tienen que ser caras bonitas, pero si atractivos; me refiero a un desarrollo de personalidad y a un gran trabajo de ingeniería de imagen". Ella afirma que el impacto de la imagen de un artista escénico ha ido evolucionado con el tiempo, ya que hace unos treinta años no se le daba la misma importancia a la apariencia física como en la actualidad:

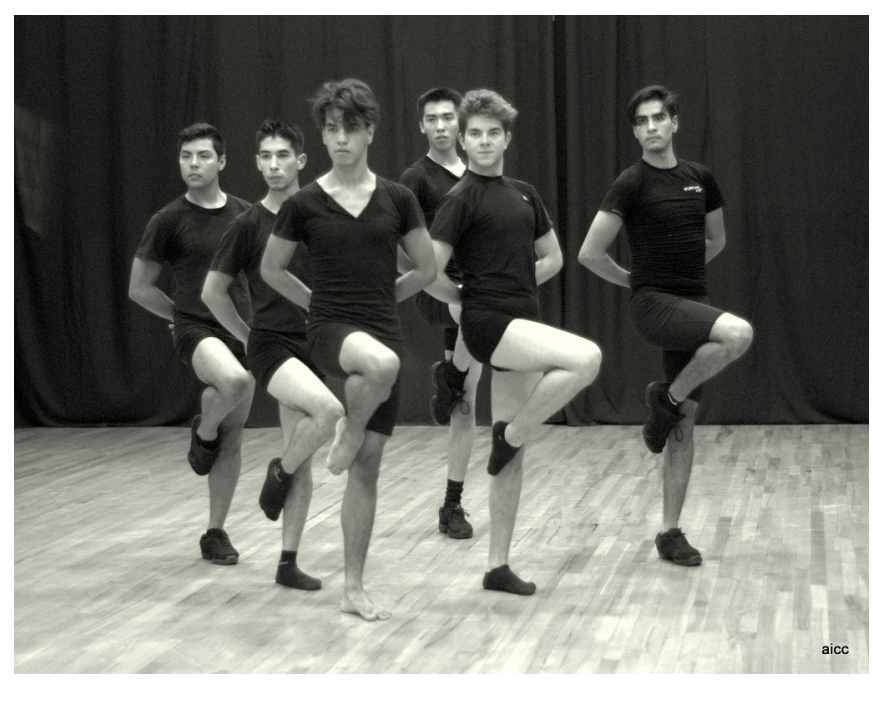

Fotografia: Ana Isabel Campillo 
"Ahora te encuentras cantantes con un talento extraordinario, con caras bonitas, cuerpos de revista, que estudiaron en universidades importantes, hablan más de cuatro idiomas, pueden hacer más de una disciplina artística, con un curriculum impresionante a su joven edad"2.

Con esta respuesta María Collura dice que el artista debe trabajar muy duro para convertirse en ello y además parecerlo, "si alguien es pero no parece pasará desapercibido; alguien que parece pero no es engañará; alguien que parece y es tendrá mucha ventaja ante sus competidores".

Teresa Rodríguez es una pionera del arte vocal de nuestro país, su trabajo como coach de ópera ha sido muy importante para proyectar a cantantes mexicanos en el extranjero. Es directora del Taller de Ópera de la Sociedad Internacional de Valores de Arte Mexicano (SIVAM). Ella opina que la ópera ha evolucionado significativamente en la última década y que la apariencia física de los cantantes ahora ha tomado un papel muy importante. Ella afirma que el Metropolitan Opera House (MET) ha marcado las tendencias que ahora se siguen a nivel mundial en la ópera. "El MET puso a las caras bonitas en el escenario y a partir de ahí todos los cantantes se pusieron a dieta, se pusieron fajas reductivas, todos van al gimnasio y al nutriólogo".

Al comentarle sobre los resultados que obtuve con las encuestas realizadas a los estudiantes de artes escénicas y música de la Universidad de Sonora, Teresa Rodríguez se mostró en desacuerdo.

"No estoy de acuerdo con los resultados que obtuviste en las encuestas realizadas en la Universidad de Sonora, ¿quieren ser músicos sin preocuparse por la imagen? Pues dedíquense a otra cosa, a no ser figuras del escenario, ese sería mi consejo. Si no te interesa puedes ser otra cosa, a lo mejor puedes ser escritor o astronauta y andar con un casco" $"$.

De aquí se desprende la importancia de este tipo de conocimientos desde la formación académica.

Flor Herrera es docente en la Universidad de Sonora, cantante de ópera y Coach; además es encargada del proceso de selección de aspirantes eArtescénica, una asociación que contribuye al arte vocal en México.

Al preguntarle cuál es la importancia de la imagen física de un cantante en una audición ella explicó su procedimiento:

"Cuando selecciono a un aspirante no sólo lo hago por cuestión de formación, pienso en que tiene que estar enfrente de un escenario, y debo pensar que es lo que quiere ver la gente. Si no me gusta tal chico o chica en la audición y no lo quiero para determinado personaje por supuesto que no le daré el papel"4.

Además, la maestra Herrera opina que actualmente las tendencias en imagen física para los cantantes de ópera son las mismas que para los cantantes de pop. "Así como los cantantes de pop poseen a todo un equipo de expertos que los producen, el cantante de ópera también lo necesita". Otro personaje destacado para las artes escénicas en México es María Morett, quien es una importante actriz, dramaturga y productora de teatro y ópera. Ella opina que la competencia recientemente ha aumentado, ya que existen muchos cantantes que son atractivos físicamente y que tienen voces bellas, lo cual es un punto más a considerar como una ventaja que los cantantes tienen que desarrollar.

"Es importante que los artistas se den cuenta que en el mercado laboral sí importa la imagen. ¿A Anna Netrebko no le importará la mercadotecnia? Seguramente tiene un departamento que la maquilla, que le dice que decir y que no decir, y por algo está posicionada como una de las mejores cantantes de ópera de actualidad"5.

María Morett, como encargada de elegir al elenco, dice que para ella es importante que 
el artista parezca y refleje su profesionalismo en su imagen, ya que esto es fundamental para que ella tome la decisión de elegirlo o no.

"Cuando un artista va vestido como sea a una audición, me transmite que le da igual si se queda o no, en cambio si vas adecuadamente, el productor puede decir: si puedes estar en este vagón. Dejar esto de la imagen a la suerte no creo que sea lo más inteligente. Si veo en el escenario a una persona que no me llama la atención pues la borro. Para mi tiene que ver si la persona tiene fuerza y presencia escénica, pero si son agradables es mejor aún”.

La opinión de María Morett nos da una idea clara de la importancia de lo que comunica nuestro vestuario, ya que como un elemento de lenguaje no verbal nuestra manera de vestirnos estará enviando mensajes y más en un momento tan importante para el artista como lo son las audiciones.

\section{Conclusiones}

La información anterior es útil para reconocer cómo en el medio artístico los empleadores valoran la imagen física del artista.

La importancia de introducir la imagen como una asignatura en la formación de los artistas escénicos y que los estudiantes revaloren la importancia que juega en su desarrollo como futuro profesional.

Ahora que se conoce la opinión de los expertos es momento de preocuparse más por la imagen, ya que para ventaja y desgracia de muchos artistas la primera impresión entra por los ojos, y es en ese momento en que se recibe la aceptación del público o su rechazo.

María Collura recomienda tomar en cuenta que la imagen es importante en todo momento, no solo al subir al escenario, también en las audiciones, al conocer a algún productor e incluso al convivir con otros artistas. Como menciona Víctor Gordoa en su libro Imagen Vendedora, la imagen será producto de los estímulos que enviemos y reflejo de la manera en cómo somos percibidos, y que la opinión colectiva que se tenga de nosotros será nuestra imagen pública (2007).

La apariencia física de un artista escénico sí importa en todo momento y por imagen no solo debemos pensar en la belleza física, aunque esta misma es un valor agregado pero no una garantía del éxito. La imagen que el artista debe cuidar se refiere al manejo de la percepción que las personas que lo rodean tienen de él. Desarrollar una buena imagen será una ventaja competitiva que será de gran utilidad para poder enfrentarnos a las crueldades del mundo laboral actual. No se trata de una cuestión de dinero, sino de saber utilizar de manera adecuada los elementos con los que enviamos mensajes verbales y no verbales, se trata de la forma y del contenido. Hay especialistas que pueden ayudarnos a mejorar nuestra imagen como los consultores en imagen pública e incluso los "Artist Coaches" que sabrán guiarnos por un buen camino en el terreno de la imagen.

\footnotetext{
Notas:

${ }^{1}$ Ventaja competitiva es un concepto de la economía, se refiere a la creación, producción, venta y entrega de un producto. De manera específica, a la realización de las actividades anteriores de manera más rápida, con menores costos de entrada y con mayor calidad que los competidores.

${ }^{2}$ Entrevista telefónica realizada el 28 de diciembre del año 2015.

${ }^{3}$ Entrevista realizada el 27 de noviembre del año 2015. Hermosillo, Sonora.

${ }^{4}$ Entrevista realizada el 20 de noviembre del año 2015. Hermosillo, Sonora.

${ }^{5}$ Entrevista realizada el 13 de enero del año 2016. Oaxaca de Juárez, Oaxaca.

Bibliografía

Moreno, L. (19 de Febrero de 2015). Club lenguaje no verbal. Obtenido de Club lenguaje no verbal: http://www.clublenguajenoverbal.com/?p=2541

Gordoa, A. (2016). A los guapos les va mejor. [online] Martha Debayle. Available at: http://www. marthadebayle.com/sitio/md/radio/guapos-les-va-mejor/ [Accessed 1 Feb. 2016].

----- y Arvizu, U. (2008). Imagen cool. México, D.F.: Grijalbo.

Gordoa, V. (n.d.). El poder de la imágen pública. 3a ed. Mexico, D.F.: EDAMEX.

-----. (2007). Imagen vendedora. México: Grijalbo.
} 